\title{
Editor's Note: Special Issue on Design and Implementation of Signal Processing Systems
}

\section{Emmanuel Boutillon ${ }^{1} \cdot$ Andreas Burg ${ }^{2}$}

Published online: 16 August 2019

(C) Springer Science+Business Media, LLC, part of Springer Nature 2019

Journal of Signal Processing Systems gratefully acknowledges the editorial work of the scholars listed above on the special issue entitled "Design and Implementation of Signal Processing Systems".

Publisher's Note Springer Nature remains neutral with regard to jurisdictional claims in published maps and institutional affiliations.

$\triangle$ Andreas Burg

andreas.burg@epfl.ch

1 Lab-STICC, Centre de recherché, Université de Bretagne Sud, 56325 Lorient, Cedex, France

2 EPFL STI IEL TCL, ELG 030 (Bâtiment ELG), Station 11, CH-1015 Lausanne, Switzerland 